\title{
Reflective Practice: How the World Bank Explored Its Own Biases?
}

\author{
Martin McKee $^{1^{*}}$, David Stuckler ${ }^{2}$
}

\begin{abstract}
While many international organisations have independent evaluations, including the International Monetary Fund (IMF) and World Health organization (WHO), uniquely the World Bank in its 2015 World Development Report sought to ascertain the potential biases that influence how its staff interpret evidence and influence policy. Here, we describe the World Bank's study design, including experiments to ascertain the impact on Bank staff's judgements of complexity, confirmation bias, sunk cost bias, and an understanding of the wishes of those whom they seek to help. We then review the Bank's proposed mechanisms to minimise the impact of the biases they identified. We argue that this approach, that we refer to as 'reflective practice', deserves to be adopted more widely among institutions that seek to use evidence from research to inform policy and practice. Keywords: Reflective Practice, Cognitive Bias, Complexity, Evidence

Copyright: (c) 2016 by Kerman University of Medical Sciences

Citation: McKee M, Stuckler D. Reflective practice: how the World Bank explored its own biases? Int J Health

Policy Manag. 2016;5(2):79-82. doi:10.15171/ijhpm.2015.216
\end{abstract}

Article History:

Received: 9 October 2015 Accepted: 9 December 2015 ePublished: 10 December 2015

\section{On Advising Others}

International organisations often give advice - to others. They analyse the world as they see it, review the evidence they have found, and offer prescriptions, frequently to governments, about what should be done. Take, for example, recent World Health Reports, published by the World Health Organization (WHO), which propose measures to achieve universal health coverage, strengthen primary care, increase global health security, and tackle the AIDS epidemic. UNICEF's State of the World's Children reports have recently looked at data for policy ("every child counts"), children with disabilities, and children in urban settings.

Sometimes the organisations writing these reports do reflect on what they, themselves are doing, particularly when things have gone wrong. The International Monetary Fund (IMF), for example, has an Independent Evaluation Office (although the IMF has been criticised for not heeding its findings). The WHO recently launched an investigation into its heavily criticised response to the Ebola outbreak. ${ }^{1}$ It is, however, very rare for international organisations to reflect publicly on how they think about the world and what this means for the policies they recommend.

Yet this is just what the World Bank has now done. The researchers preparing the 2015 World Development Report ${ }^{2}$ have looked at how individual World Bank staff make decisions, drawing on theory and empirical research to challenge the ideologies that members of its staff may hold. The World Bank study - a rare case of analysis of an institution's own potential internal and subconscious biases - arose from concerns within the Bank that its staff were making decisions that did not reflect reality on the ground. The authors invoked a study showing that $42 \%$ of Bank staff predicted that 'most of the poor' in Nairobi would agree with the statement that "vaccines are risky because they can cause sterilization," yet in fact only $11 \%$ of those poor people who were surveyed in Nairobi did agree with it. Moreover, immunisation rates in that population exceeded $80 \%$. Importantly, proximity to the poor had little effect; they found minimal difference between staff in country offices and those in the Washington headquarters, or between those working on poverty and those working on other issues. They concluded that there was a "shared mental model, not tempered by direct exposure to poverty" in the Bank, which acted as an organisational ideology, incubated and spread throughout the institution's culture.

In this editorial, we review what the World Bank did, including the experiments it undertook to understand how its staff make decisions and the extent to which they empathised (or not) with the lives of those whom they wish to help. We conclude with recommendations for all organisations working in the international development arena, based on what the Bank found. Before turning to the Bank's study, however, we first briefly situate the study within the broader context in which those offering policy advice, such as the Bank's staff, operate.

\section{Making Decisions in a Complex World}

Many factors influence how decision-makers respond to evidence. Faced with the complex reality of the world, decisionmaking is rarely simply a technical process, where decisions can be made simply by feeding data into an algorithm. ${ }^{3}$ To take just a few examples, first there may be multiple objectives that are being pursued, such as improving healthcare while constraining costs. Second, the impact of a decision may vary over time, as when short-term savings lead to greater longterm costs, so that choices may be determined by the electoral cycle. Third, there may be winners and losers. Nearly all major public policy decisions involve a degree of redistribution and whether that is seen as acceptable depends on many factors, including the ability of each group to articulate its interests 
and the dominant political ideology. Fourth, and regrettably common, there may be hidden agendas, including corruption and vested interests.

Even when the goals are clear and agreed upon, there are many factors that influence what knowledge is used to inform decisions and how it is used. ${ }^{4}$ For example, decision-makers may or may not draw on both explicit and tacit knowledge, the former capable of being stated, usually with reference to published work, while the latter is often unstated, associated with experience of what does or does not work in particular circumstances. ${ }^{5}$ They might use this knowledge in ways that are instrumental, leading to changes in behaviour and practice; conceptual, to achieve changes in knowledge, understanding and attitudes; or symbolic, to add legitimacy to decisions they have already made. ${ }^{6}$ Thus, as this brief and, of necessity, selective review shows, decision-making in public policy is complicated and there are rarely answers that are definitively "right" or "wrong." However, there may be some things that can be done to ensure that those decisions that are made are at least consistent with the goals that the organisation has made explicit and that knowledge that is cited is drawn on accurately and used effectively for achieving those goals. To this end, the researchers preparing the 2015 World Development Report ${ }^{2}$ focussed on one discrete issue that affects how World Bank staff make decisions. This is the role played by cognitive biases, where different people, presented with the same evidence, reach very different conclusions.?

\section{What are Cognitive Biases?}

Cognitive biases gained widespread attention following the publication of a seminal study by Tversky and Kahneman, in 1974, who showed how people use heuristics, or mental shortcuts, when faced with complex choices. ${ }^{8}$ They argued that these were often the only practical way that a decision could be made and thus had considerable practical value, although they also carried considerable risk of mistakes. These came about when the decision-making process involved cognitive biases. These include ignoring relevant information or placing undue emphasis on unimportant, though salient aspects of the issue (anchoring). There are many different types of cognitive bias but specific examples that may influence decision-making include confirmation bias, where individuals seek out information from sources likely to take the same view that they do, ${ }^{9}$ self-serving bias, where they evaluate evidence in ways that are likely to be advantageous to their interests, ${ }^{10}$ belief bias, where the strength of the evidence is assessed according to whether one agrees with the resulting conclusion, ${ }^{11}$ and framing bias, where the social construction of the issue increases the probability of particular decisions being made (Box). ${ }^{12}$

\section{What the World Bank Did}

The Bank's researchers explored four issues related to bias and the circumstances in which it may arise: complexity; confirmation bias; sunk cost bias, and an inability to place oneself in the situation of others. While recognising that there are others that could be examined, we will now review in turn how they addressed each of these.

As noted above, many decisions involve complexity, in which policy-makers must decide among multiple options. The World Bank researchers illustrate the challenges involved with a study in which physicians were presented with a scenario involving a patient with chronic hip pain. ${ }^{17}$ Half were told they could choose between immediate referral for possible surgery and initiation of a specific medical treatment that, they were told, had not yet been tried in that patient. The other half were given the same options plus a third, referral and a second treatment. Significantly more chose referral alone, the simplest option, when confronted with the more complex scenario, suggesting that the addition of even a very minor increment in complexity can cause people to adopt the easiest course, even if it means denying the patient a potentially effective treatment.

The Bank's researchers also highlight the importance of framing. Here they cite a seminal study by Tversky and Kahneman, in which some subjects are confronted with a situation in which, if they do nothing, a third of the population will live but if they act there is a $33 \%$ chance of saving everyone and a $66 \%$ chance of saving no one. ${ }^{18}$ Others face a situation in which, if nothing is done, two-thirds of the population will definitely die but if they act there is a $33 \%$ chance that no-one will die and a $66 \%$ chance that everyone will die. Of course, the two scenarios are numerically identical but those given the first scenario, framed in terms of gains, preferred certainty

\section{Box. Selected Examples of Cognitive Bias}

- Framing bias was demonstrated by Parkhurst in a study of how it influenced assessments of the effectiveness of the $\mathrm{ABC}$ ('abstinence, be faithful, and correct and consistent condom use') policy advocated to reduce HIV transmission in Uganda. ${ }^{13} \mathrm{He}$ shows how those involved in the exchange of information interpret the evidence in the light of their "internally consistent belief systems" which led to different conclusions. ${ }^{14}$

- Confirmation bias was apparent in a study where volunteers were given the opportunity to search online for information to answer a question posed to them and had their eye movements and mouse clicks are tracked. They systematically searched out evidence from sources they thought will support them and disregarded evidence from sources with which they disagreed. ${ }^{15}$

- Belief bias was seen in a randomised controlled trial conducted with American subjects who were first divided according to their political allegiance and then randomly allocated one of four authoritative narratives about diabetes, no specific cause (control), genes, lifestyle choices, and the social environment. Democrats receiving the narrative setting out the social factors, such as the well-established obesogenic environment, were more likely than controls to support collective action while Republicans became less likely to support it. ${ }^{16}$ 
and avoided the risk of action. Those faced with the second scenario, framed in terms of losses, were much more likely to take a chance. Even though this experiment is well-known, when the Bank researchers replicated it among Bank staff they found that framing was important; $75 \%$ chose certainty when faced with the gain framing but only $34 \%$ of those presented with the loss framing did so.

Confirmation bias exists where individuals systematically search for evidence that supports their preconceived view and discard evidence that challenges it, as in the examples cited earlier. Importantly, this is not a matter of ability to understand information. The Bank researchers cite an earlier study in which individuals were presented with identical data, but framed either in relation to the effectiveness of skin cream (uncontentious) or gun control (highly contentious). ${ }^{19}$ Greater numeracy did help overall interpretation of the data framed as a skin cream issue but was only beneficial among those who were already supportive of gun control. Indeed, the strongest determinant of getting the right answer was the subject's prior belief. The Bank researchers replicated the experiment, retaining the skin cream example and replacing gun control with legislation for a minimum wage, comparing those who supported one of two conflicting statements on the desirability of reducing income inequality. As in the original study, the main determinant of whether a subject correctly interpreted the data framed as a wage issue was their prior belief.

The researchers also looked at a bias that is of particular relevance to a development agency such as the Bank. This is "sunk cost bias," whereby, even where there is clear evidence of failure, subjects told that a higher proportion of the budget for a project has already been spent are more likely to support the project's continuation. ${ }^{20}$ The Bank researchers tested for this by giving staff a series of scenarios in which the proportion of total funds committed for a conservation project increased but the provincial government announced a hydroelectric programme that would mean that none of the benefits would be realised. Even though the two schemes were totally in conflict, support for continuation of the conservation scheme increased as the sunk costs became higher. Although there are other possible explanations, such as an unwillingness to concede failure, the observation that this increasing support grew linearly with greater sunk costs indicates that this particular bias was important.

A final set of biases, again especially relevant in a development agency, arise from what the Bank staff described as the inability of one group of people to put themselves in the situation of another, although this might be described more succinctly as an inability to empathise. Wealthy people, such as World Bank staff and consultants, tend to prioritise time over money. Thus, when asked if they would drive for 45 minutes to save $\$ 50$, they might do so when they can get a $\$ 150$ purchase for $\$ 100$ but are less likely to do so if they are saving the same amount on a $\$ 500$ purchase. ${ }^{21}$ For a poor person, the absolute value, in terms of time, of saving $\$ 50$ is the same whatever the base cost. Once again, the Bank researchers were able to confirm this in a comparison of Bank staff and low-income inhabitants of Nairobi. The researchers also asked Bank staff about how they felt poor people in Lima, Jakarta, and Nairobi would respond to questions on the control they had over their lives and to compare it with how they themselves would answer. They considered that the poor in these three cities would express high levels of helplessness but in fact poor people had views that were much closer to those of Bank staff.

\section{Conclusion}

It is not enough to produce more research. What we are learning from cognitive psychology is that, even when armed with evidence, and a willingness to use it, "good people can make bad decisions." ${ }^{2}$ In this way, perversely, the bestintentioned researchers can inadvertently work against the interests of those they are meant to be helping. Crucially, cognitive biases can be remarkably resistant to change. Thus, even when false statements are corrected by an authoritative source, if the original statement aligns with the prior beliefs of the subject, the correction often simply reinforces the false belief. $^{22}$

There are several possible remedies. The first is recognition of the problem. Awareness that these biases exist and often lead to bad decisions can help safeguard against their influence. The second is to put in place measures that can improve decision-making. For example, confirmation bias may be addressed by ensuring that a diversity of views are considered. In the military, so-called red teaming involves bringing in a group who will challenge, in an adversarial manner, the key assumptions underpinning the decision. ${ }^{23}$ There is also a range of formal decision analysis tools that can be used. Similarly, sunk cost bias can be addressed by creating a culture that is less punitive and enable open and frank discussion about errors, recognising that when things go wrong there are opportunities to learn lessons for the future. A third approach is to set up institutional mechanisms to 'reverse the nouns' - encouraging those involved in development to take steps to look at the programs they are supporting through the eyes of those who are using them. There is a growing body of multimethod research that seeks to do this, identifying the challenges that users of health and other services face on an everyday basis and tracing back through the system to identify the causes of these problems. ${ }^{24,25}$

National and international organisations have much to learn from this valuable exercise undertaken by the World Bank. All organisations, and individuals, make mistakes. Some do so with remarkable regularity. It is much less common to find one that is willing to acknowledge its mistakes, to assess and confront its biases, and to put in place policies and practices to overcome them. A first step is to begin to understand the subconscious biases, and the cultures that perpetuate them, which impact us all.

Ethical issues

Not applicable.

Competing interests

DS has no competing interests. MM has previously worked as a consultant to the World Bank.

Authors' contributions

Both authors contributed equally to the writing of this article.

\section{Authors' affiliations}

${ }^{1}$ Department of Health Services Research and Policy, London School of Hygiene and Tropical Medicine, London, UK. ${ }^{2}$ Department of Sociology, University of Oxford, Oxford, UK. 


\section{References}

1. Panel of independent experts. Report of the Ebola Interim Assessment Panel - July 2015. Geneva: WHO; 2015.

2. Bank W. World Development Report 2015: Mind, Society, and Behavior. Washington DC: World Bank; 2014.

3. Weiss $\mathrm{CH}$. Research for policy's sake: the enlightenment function of social research. Policy Analysis. 1977;3(4):531-545.

4. Nutley S, Walter I, Davies HT. From knowing to doing a framework for understanding the evidence-into-practice agenda. Evaluation. 2003;9(2):125-148. doi:10.1177/1356389003009002002

5. Collins H. Tacit and explicit knowledge. Chicago: University of Chicago Press; 2010.

6. Amara N, Ouimet M, Landry R. New evidence on instrumental, conceptual, and symbolic utilization of university research in government agencies. Science Communication. 2004;26(1):75106. doi:10.1177/1075547004267491

7. McKee M, Stuckler D. How cognitive biases affect our interpretation of political messages. Bmj. 2010;340:c2276. doi:10.1136/bmj.c2276

8. Tversky A, Kahneman D. Judgment under uncertainty: Heuristics and biases. Science. 1974;185(4157):1124-1131. doi:10.1126/ science.185.4157.1124

9. Nickerson RS. Confirmation bias: A ubiquitous phenomenon in many guises. Rev Gen Psychol. 1998;2(2):175. doi:10.1037//1089-2680.2.2.175

10. Babcock L, Wang X, Loewenstein G. Choosing the wrong pond: Social comparisons in negotiations that reflect a self-serving bias. Q J Econ. 1996;111(1):1-19. doi:10.2307/2946655

11. Leighton JP, Sternberg RJ. The nature of reasoning. Cambridge: Cambridge University Press; 2004.

12. Druckman JN. The implications of framing effects for citizen competence. Political Behavior. 2001;23(3):225-256.

13. Parkhurst JO. Framing, ideology and evidence: Uganda's HIV success and the development of PEPFAR's' ABC'policy for HIV prevention. Evidence \& Policy: A Journal of Research, Debate and Practice. 2012;8(1):17-36. doi:10.1332/174426412x620119

14. Sabatier PA. An advocacy coalition framework of policy change and the role of policy-oriented learning therein. Policy Sciences.
1988;21(2-3):129-168. doi:10.1007/bf00136406

15. Taber CS, Lodge M. Motivated skepticism in the evaluation of political beliefs. Am J Pol Sci. 2006;50(3):755-769. doi:10.1111/ j.1540-5907.2006.00214.x

16. Gollust SE, Lantz PM, Ubel PA. The polarizing effect of news media messages about the social determinants of health. Am J Public Health. 2009;99(12):2160-2167. doi:10.2105/ ajph.2009.161414

17. Redelmeier DA, Shafir E. Medical decision making in situations that offer multiple alternatives. JAMA. 1995;273(4):302-305. doi:10.1001/jama.273.4.302

18. Tversky A, Kahneman D. The framing of decisions and the psychology of choice. Science. 1981;211(4481):453-458. doi:10.1126/science.7455683

19. Kahan DM, Peters E, Dawson EC, Slovic P. Motivated numeracy and enlightened self-government. Yale Law School, Public Law Working Paper; 2013.

20. Arkes HR, Blumer C. The psychology of sunk cost. Organ Behav Hum Decis Process. 1985;35(1):124-140. doi:10.1016/07495978(85)90049-4

21. Mullainathan S, Shafir E. Scarcity: Why having too little means so much. Macmillan; 2013.

22. Nyhan B, Reifler J. When corrections fail: The persistence of political misperceptions. Political Behavior. 2010;32(2):303-330. doi:10.1007/s11109-010-9112-2

23. Yang $A$, Abbass $H$, Sarker $R$. Characterizing warfare in red teaming. Systems, Man, and Cybernetics, Part B: Cybernetics, IEEE Transactions on. 2006;36(2):268-285. doi:10.1109/ tsmcb.2005.855569

24. Risso-Gill I, Balabanova D, Majid F, et al. Understanding the modifiable health systems barriers to hypertension management in Malaysia: a multi-method health systems appraisal approach. BMC Health Serv Res. 2015;15:254. doi:10.1186/s12913-0150916-y

25. Kuhlbrandt C, Balabanova D, Chikovani I, et al. In search of patient-centred care in middle income countries: the experience of diabetes care in the former Soviet Union. Health Policy. 2014;118(2):193-200. doi:10.1016/j.healthpol.2014.08.009 